\title{
The Appropriateness of Default Investment Options in Defined Contribution Plans: Australian Evidence
}

\author{
Anup K. Basu \\ Senior Lecturer of Finance \\ School of Economics and Finance \\ Queensland University of Technology \\ Brisbane 4001 \\ Australia \\ Phone + $61(0) 731388377$ \\ $\mathrm{Fax}+61(0) 731381500$ \\ E-mail: a.basu@qut.edu.au
}

\author{
Michael E. Drew* \\ Professor of Finance \\ Griffith Business School \\ Griffith University \\ Nathan 4111 \\ Australia \\ Phone $+61(0) 737355311$ \\ Fax $+61(0) 737353719$ \\ E-mail: michael.drew@griffith.edu.au
}

\begin{abstract}
For participants in defined contribution (DC) plans who refrain from exercising investment choice, plan contributions are invested following the default investment option of their respective plans. Since default investment options of different plans vary widely in terms of their benchmark asset allocation, the most important determinant of investment performance, participants enrolled in these options face significantly different wealth outcomes at retirement. This paper simulates the terminal wealth outcomes under different static asset allocation strategies to evaluate their relative appeal as default investment choice in DC plans. We find that strategies with moderate allocation to stocks are consistently outperformed in terms of upside potential of exceeding the participant's wealth accumulation target at retirement as well as downside risk of falling below that target outcome by very aggressive strategies whose allocation to stocks approach $100 \%$. The risk of extremely adverse wealth outcomes for plan participants also does not appear to be very sensitive to asset allocation. Our evidence suggests the appropriateness of strategies heavily tilted towards stocks to be nominated as default investment options in DC plans unless plan providers emphasize predictability of wealth outcomes over adequacy of retirement wealth.
\end{abstract}

JEL Code: $\quad$ G23, G11

Keywords: $\quad$ Defined Contribution; Default option; Pensions.

* Corresponding author. Drew gratefully acknowledges the financial support of the Australian Research Council's Discovery Grant funding scheme (DP0452336). We gratefully acknowledge the contribution of the Managing Editor, Professor Charles $\mathrm{Cao}$ and the suggestions of the anonymous reviewers which improved the paper. We thank Robert Bianchi (Griffith), Evan Reedman (JANA), Martin Gruber (NYU) and Adam Walk (QIC) and participants at the Northern Finance Conference (2006) for comments. 


\section{The Appropriateness of Default Investment Options in Defined Contribution Plans: Australian Evidence}

\section{INTRODUCTION}

IN MOST DEVELOPED COUNTRIES, THE COINCIDENCE of a rapidly aging population with a rising proportion of retirees is placing considerable pressure on current social security programs. The situation has prompted policymakers to encourage funded private retirement plans (generally sponsored by employers or other private providers) known as defined contribution (DC) plans, where employee participants build up retirement savings through mandatory or voluntary contributions in their individual retirement accounts. A growing trend in DC plans is to give the individual participants more control over investment of their plan assets. This investment decision is critical because it determines future investment returns on their plan assets, and therefore, influences the wealth accumulated in the retirement account at the end of the participant's working life.

A substantial body of recent research demonstrates that although members of retirement plans have the option to exercise choice, most accept the default arrangements in the plans. In USA, Choi, Laibson, Madrian, and Metrick (2003) find that up to $80 \%$ of assets in different plans are invested in the default fund. According to consulting firm Hewitt Bacon and Woodrow, around $80 \%$ of group personal pension scheme members in UK accept the default option provided by their plans (Bridgeland, 2002). Similarly, Cronqvist and Thaler (2004) find that since 2003 only $10 \%$ of the new participants in Swedish retirement plans actually made any choice. In Australia, nearly half of all of all retirement plan assets are invested in default investment options (APRA, 2008). It seems that for a large majority of DC plan participants worldwide, the investment of plan contributions are dictated by the default arrangement of their respective plans.

Given that most plan participants tend to accept default investment options in their plans, perhaps it is more important, from a practical standpoint, to question whether these default investment options are appropriately designed to meet the retirement goals of the participants. This issue has received little research interest, which is surprising because financial well being for the majority of plan participants after retirement is directly linked to the performance of the 
default options. Moreover, international evidence, including Blake, Byrne, Cairns, and Dowd (2004), indicates there is serious lack of agreement on this subject which is reflected in the wide disparity in benchmark asset allocation of default funds chosen by different plan providers.

The question of appropriateness of the default options is no less pertinent for countries where these are less heterogeneous in terms of strategic asset allocation. For instance, Utkus (2004) points out that majority of the plans in the United States (US) choose a money market or stable value fund as default investment option although such arrangements are inconsistent with two of the 'prudent investor' principles on asset allocation underlying most participant education programs: first, the existence of positive equity risk premium; and, secondly, the change in the investor's risk-taking capacity with age. ${ }^{1}$

The importance of asset allocation in influencing investment performance has been well demonstrated by many researchers (Brinson, Hood, and Beebower, 1986; Blake, Lehmann, and Timmermann, 1999). Therefore, one would expect that the asset allocation strategies of default options are decided with utmost care - not only because a majority of participants passively accept the default options offered by their plans - but also considering that there is evidence (Madrian and Shea, 2001; Beshears, Choi, Laibson and Madrian, 2006) to suggest that many individuals perceive the default choice as recommendation or endorsement of a particular course of action by the provider. This implies that once the participants get enrolled in the default option in their plans, they are also likely to persist with it for much of their working lives.

In this paper, we examine the appropriateness of various asset allocation strategies representative of those adopted by DC plans in Australia as default options. We find the case of Australian DC plans interesting for three reasons. First, Australia has a well established private retirement system with $80 \%$ of all retirement plan assets allocated to DC plans (APRA, 2008). Since 1992, the Australian Government has made it compulsory for all employers to make contributions to these plans (known as 'superannuation funds') on behalf of their employees (members) at a minimum specified rate (currently $9 \%$ of wage and salary).

Second, members in Australian superannuation funds directly confront the classical portfolio choice problem as they are expected to choose an asset allocation strategy (or a combination of

\footnotetext{
${ }^{1}$ Utkus (2004) also observes that extant legal provisions permit investments that result in short-term losses to pursue long term gains and do not require the trustees to invest in 'safe' assets. The Pension Protection Act of 2006 offers safe harbour relief to fiduciary liability to investment outcomes under certain conditions including one that specifies assets must be invested in a 'qualified default investment alternative' as defined in the regulation.
} 
strategies) from a menu of pre-selected asset allocation strategies provided by the plan providers to invest plan contributions. This is different from say $401(\mathrm{k})$ plans in USA where participants are offered a choice of mutual funds rather than actual asset classes (though in many cases these are representative of such asset classes). Finally, to examine the issue of effectiveness of any strategic asset allocation policy in the context of wealth accumulation in DC plans, we need to consider its optimality from the perspective of an investor with a long horizon, typically equalling at least the participant's employment life. Unlike $401(\mathrm{k})$ plans in USA that may allow distribution of account balances for participants who change jobs as well as include loan features against account balances, superannuation funds in Australia are prohibited from permitting withdrawal of superannuation assets by members before they reach the preservation age (currently 60 years for those born after June 1964). ${ }^{2}$ Therefore, the asset allocation structure of the default options offered by Australian pension funds can be expected to be designed from a truly long term perspective and less concerned with the impact of short term volatility in returns on the participant's account balance.

Past research on DC plan investment choices have mostly examined hypothetical asset allocation strategies. In contrast, our study considers asset allocation strategies which are based on those actually used by plan providers as default investment choices. Unlike Poterba, Rauh, Venti, and Wise (2006) who attempt to rank wealth outcomes associated with different asset allocation strategies for 401(k) plans by using utility function of retirement wealth, we use riskadjusted performance measures to avoid making specific assumptions about the form of the utility function of DC plan participants. Also, in contrast to most other studies, we consider downside risk (the risk of the participants falling short of reaching their target wealth accumulation at retirement) as an important criterion in selecting an appropriate default strategy for DC plans. Since the risk of extreme events can also influence the plan providers' choice of default options, we rank asset allocation strategies in terms of their ability to reduce the potential and severity of the most adverse outcomes.

The remainder of this paper is organized as follows. The following section discusses the metrics used to evaluate different asset allocation strategies. The next two sections describe the simulation methodology and the data. Subsequently we discuss the simulation results before providing concluding comments in the final section.

\footnotetext{
${ }^{2}$ Restricted withdrawals are permitted in some extreme circumstances.
} 


\section{Metrics for Evaluating Retirement Wealth OUtcomes}

To evaluate asset allocation strategies and assess their appropriateness as default investment options in DC plans, we need to make plausible assumptions about the rationale that may guide the selection of a specific asset allocation strategy as a default option from many competing candidates. The basic motivation behind instituting retirement savings plans is to generate adequate income for the participating employees after retirement. In that case, performance of DC plans should be measured in terms of their ability to generate sufficient retirement income (Baker, Logue, and Rader, 2005). Therefore, the principal investment objective of such plans would be to maximize the terminal value of plan assets at the point of retirement since that would directly determine the amount of annuity the retiring employees are able to purchase for sustenance during post-retirement life. ${ }^{3}$ Past studies have mainly considered the absolute value of the participant's accumulated assets at retirement. However, we employ a ratio which compares the terminal wealth of the participant's retirement account to their terminal income because it is very likely that the participant's post-retirement income expectations are closely linked to their immediate income before retirement. ${ }^{4}$ We call this measure the 'retirement wealth ratio' $(R W R)$.

Higher estimates of different measures of $R W R$ outcomes (like mean or median) do not automatically qualify a particular strategy to be selected as default option. The trustees also need to consider the risk associated with investment of plan assets since participants would want a better exploitation of trade-off between risk and reward. In this study we use shortfall below target outcomes (instead of variability of terminal wealth outcomes given by their standard deviation) as measure of risk. Since we assume that the ultimate goal of the DC plan participants is to attain a specific amount of wealth in DC plan account relative to their terminal income, which we call the target retirement wealth ratio $\left(R W R_{T}\right)$, the investment risk most relevant to

\footnotetext{
${ }^{3}$ Our choice of terminal wealth (instead of pension annuities) as a measure of retirement welfare is driven by the characteristics of Australian superannuation where retirement benefits are typically drawn as lump sum on retirement and not as annuities.

${ }^{4}$ This is supported by Booth and Yakoubov (2000), who employ a similar benchmark, that is, the value of the accumulation fund at retirement in terms of employee's salary. In addition, this study uses a broader range of metrics in evaluating the risk-reward characteristics of the outcomes.
} 
participants is that of failure of their chosen asset allocation strategy to generate $R W R_{T}{ }^{5}$ Olsen (1997) finds that two of the most important attributes of perceived investment risk are potential for below target returns and potential for large loss. We capture these two risk attributes by employing downside risk and tail-related risk metrics respectively.

In this paper, we employ the lower partial moment (Bawa, 1975; Fishburn, 1977) to measure downside risk of different asset allocation strategies. $L P M$ can represent different attitudes of pension fund members towards risk such as risk averse, risk seeking, and risk neutral. If $\lambda$ denotes the risk tolerance of the plan participant, then lower partial moment of retirement wealth outcomes is given by:

$$
L P M_{\lambda}=\frac{1}{n} \sum_{t=1}^{n} \operatorname{Max}\left[0,\left(R W R_{T}-R W R_{t}\right)\right]^{\lambda}
$$

where $R W R_{T}$ is the target outcome, $R W R_{t}$ is the outcome for the $\mathrm{t}$ - $t$ th observation, $n$ is the number of observed $R W R$ outcomes, and Max is the maximization function that selects the larger between the numbers 0 and $\left(R W R_{T}-R W R_{t}\right)$. The term $\lambda$, which is known as the degree of $L P M$ can theoretically assume any value depending on the risk aversion of the participant.

We compute the lower partial moments for wealth outcomes under different asset allocation strategies for participants with $\lambda=0,1$, and 2 . For $\lambda=0, L P M_{0}$ gives the probability of shortfall, that is, how often the return can fall below the target although it does not consider how severe the shortfall is likely to be. If $\lambda=1, L P M_{1}$ weighs shortfalls $\left(R W R_{T}\right.$ less 'below $R W R_{T}$ ' outcomes in the context of our problem) with linear weighting. This, therefore, gives the expected shortfall of the strategy. For $\lambda=2, L P M_{2}$ gives the below-target or downside semi-variance. The choice of appropriate shortfall measure may be guided by the investor's degree of risk aversion (Bawa 1978, Harlow and Rao, 1989) with risk-averse investors choosing LPM with $\lambda>0$.

We also use performance measures which are adjusted for downside risk in evaluating alternative asset allocation strategies. The concept of downside deviation has been used to suggest several risk-adjusted performance measures, the most well-known among which is the

\footnotetext{
${ }^{5}$ This type of 'downside risk' is not new to economics and finance literature. Roy (1952) developed the target rate of return approach in a portfolio selection context where the investor is concerned about minimizing the probability of falling below the disaster level or minimum acceptable rate of return. Since then researchers have found evidence of decision makers conceiving risk as the possibility of outcomes below target (eg. Mao, 1970; Olsen, 1997)
} 
Sortino ratio (SR) introduced by Sortino and Price (1994). This is given by:

$$
S R=\frac{R W R_{M}-R W R_{T}}{\left[L P M_{2}\right]^{1 / 2}}
$$

where $R W R_{M}$ denotes the mean $R W R$. Due to its use of downside deviation as measure of risk, it does not penalise performance for volatility above the investor's target unlike the Sharpe ratio. Further, Sortino, van der Meer, and Plantinga (1999) propose a performance statistic that replaces the excess of mean above target in Sortino ratio with the upside potential of the investment, a probability weighted summation of all outcomes which are above the target. ${ }^{6}$ This gives the upside potential ratio (UPR). In the context of our problem:

$$
U P R=\frac{\sum_{R W R_{T}}^{\infty}\left(R W R-R W R_{T}\right)}{\left[L P M_{2}\right]^{1 / 2}}
$$

Next, we consider the risk of extremely adverse wealth outcomes for plan participants. Rabin and Thaler (2001) show that reasonable degrees of risk aversion for small and moderate stakes imply unreasonable high degrees of risk aversion for large stakes. If DC plan participants are believed to be loss averse towards the value of their retirement assets, which can be considered as a 'large stake', the plan sponsors may decide to select asset allocation strategies that have more chance of avoiding the most disastrous outcomes i.e. minimize tail risk. To evaluate the extreme retirement wealth outcomes of alternative asset allocation strategies, we use two common measures of estimating tail risk - value at risk (VaR) and expected tail loss (ETL). In the context of our problem, if $p$ represents the probability of worst percentage of $R W R$ outcomes that the participants are concerned about, $\alpha$ is the confidence level and $p$ is set such that $p=1-\alpha$, and if $Q_{p}$ represents the $p$-quantile of the $R W R$ distribution, then the $\mathrm{VaR}$ at that confidence level is given by:

$$
\operatorname{VaR}=Q_{p}
$$

We specify $\alpha$ at $95 \%$, which indicates the likelihood that the investor would not get an outcome worse than VaR. We also measure Expected Tail Loss (ETL), which is often proposed as a better candidate than VaR as a coherent risk measure (Artzner, Delbaen, Eber, and Heath, 1999).

\footnotetext{
${ }^{6}$ This is consistent with findings by behavioural finance researchers like Statman and Shefrin (2000) who claim that investors seek upside potential from investments while protecting the downside.
} 
ETL gives the probability weighted average of estimates that fall below VaR. In our case, if $R W R_{i}$ is the $i$ th outcome and $p_{i}$ is the probability of the $i$ th outcome, then:

$$
E T L_{\alpha}=\frac{1}{1-\alpha} \sum_{p_{i}=0}^{\alpha} R W R_{i} \cdot p_{i}
$$

Since we have specified $\alpha$ at 95\%, ETL is actually the average of the worst $5 \%$ of the $R W R$ outcomes.

Although we do not see variability of retirement wealth outcomes as risk perceived by plan participants, we use two common measures of dispersion. First, we estimate coefficient of variation $(\mathrm{CV})$ for retirement wealth outcomes under every strategy which is the standard deviation of RWR outcomes divided by the mean RWR. To supplement this metric, we also estimate the inter-quartile range ratio (IQRR) which is obtained by dividing the difference between the 75th percentile RWR and the 25th percentile RWR by the median RWR for each strategy under consideration.

\section{Model for Generating RetiRement Wealth OUtcomes}

To analyse the distribution of wealth outcomes generated by different asset allocation strategies, we use a simple DC plan accumulation model which uses stochastic simulation of asset class returns to determine the expected distribution of wealth outcome at retirement. ${ }^{7}$ As discussed in previous section, the wealth outcome is measured as retirement wealth ratio $(R W R)$. The terminal value of DC plan assets is given by:

$$
W=k \sum_{t=0}^{R-1}\left(1-e_{t}\right) S_{t}\left(1+r_{t}\right) \prod_{u=t+1}^{R-1}\left(1+r_{u}\right)
$$

where: $W=$ value of plan assets accumulated at the point of retirement

$k=$ Plan contribution rate

$e_{t}=$ Employment state in year $t$

$S_{t}=$ Annual salary in year $t$

$r_{t}=$ Real rate of investment return earned in year $t$

\footnotetext{
${ }^{7}$ Stochastic simulation is the preferred method of estimation when dealing with this type of complex situation involving future uncertainties or risk (Dowd and Blake, 2006)
} 
$R=$ Number of years in the plan before retirement

To estimate $W$, we need to model the: (i) contribution cash flows; and, (ii) investment returns for each period. The contribution cash flows depend on annual salary, contribution rate, and probability of unemployment in any period. The annual salary for any year, in turn, depends on starting wage, wage growth rate, and the number of years elapsed since commencing employment. This is given by:

$$
S_{t}=S_{0}(1+g)^{t-1}
$$

where $S_{0}$ is the starting wage of the plan participant and $g$ is the real wage growth rate.

Investment returns are dependent on returns on individual asset classes (included in the portfolio) and the weights assigned to them. The latter is determined by the asset allocation strategy of the plan. Mathematically:

$$
r_{t}=\sum w_{i, t} r_{i, t}
$$

where: $w_{i, t}$ is the weight assigned to the $i^{\text {th }}$ asset in year $t$ and $r_{i, t}$ is the real return on the $i^{\text {th }}$ asset in year $t$.

We base our analysis on simulated wealth outcomes for an employee who joins the plan at the age of 25 years and retires at the age of 65 years. The starting salary of the employee is assumed to be 25,000 Australian Dollars and the growth in real wages to be $2 \%$ per year, which closely follows growth rate of Australia's real GDP per capita of 2.6\% per annum from 1994 through 2004 (ABS, 2005). The contribution rate is fixed at 9\% which is the legislated minimum prescribed by the Australian government. Employment state is modelled as a binary variable $(0$, 1). No contribution is made during periods of unemployment, the probability of which is assumed to be $5 \%$, which is equal to the unemployment rate among Australian workers with post-school qualifications (Kryger, 1999; Richardson, 2006). For the sake of simplicity, we assume that the contributions are credited annually to the accumulation fund at the end of every year. The portfolios are also rebalanced at the end of each year to maintain the target asset allocation. We ignore any taxes payable on investment returns and transaction costs that may be incurred in managing the investments. 
To generate $r_{i, t}$, we employ two different methods: Monte Carlo and bootstrapping. This helps us to check the robustness of our results. Monte Carlo method estimates statistical parameters from historical data series under assumed theoretical distribution and then exposes these to random changes in simulating future outcomes. Following standard Monte Carlo simulation methodology, we assume that asset class returns are drawn from a multivariate normal distribution. This implies that mean and standard deviation of asset class returns are time invariant and the returns are independent over the time horizon. At each stage of the simulation horizon, the random shocks generated by the multivariate normal model are adjusted so as to follow the average cross-sectional correlation observed in the historical data. The correlationbased dependence structure for Monte Carlo analysis is derived through Cholesky decomposition. If $L_{1}=\left\lfloor l_{i j}\right\rfloor$ is the lower-triangular Cholesky decomposition of the correlation matrix $C, \mu_{i}$ be mean return on the asset $i$, and $\sigma_{i}$ be the standard deviation of return on asset $i$, then for a portfolio of $\mathrm{n}$ assets, the multivariate normal Monte Carlo model dictates that

$$
Z_{i}=\sum_{j=1}^{n} l_{i j} \xi_{j}
$$

where $\xi$ denotes an independent standard normal random variable (i.i.d. $\approx N(0,1))$ and where $Z_{i}$ represents a correlated standard normal variable for asset $i$. The simulated return on asset $i$ is then obtained as

$$
r_{i}=\mu_{i}+\sigma_{i} Z_{i}
$$

Having selected the model for generating simulated returns, the required parameters - means, standard deviations, and correlations- are estimated from historical returns data which is described in the next section.

For bootstrap simulations, asset class returns are drawn from the empirical return distribution. Here we randomly resample with replacement vectors from the matrix of annual asset class returns time series to generate portfolio returns for every period of the 40 year investment horizon of the DC plan participant. In other words, each bootstrap sample is a random sample of asset class returns for a particular period drawn with replacement from historical observations over several periods. Thus we retain the cross-correlation between the asset class returns as given by the historical data while assuming that asset class return series is independently distributed over time. 


\section{DATA}

To investigate the issue of strategic asset allocation for long horizon investors like DC plan participants it is essential that we generate simulated returns based on historical observations of asset class returns over several decades. This is done to minimize the undue influence that recent investment performances (of these asset classes) on asset allocation decisions. Longer period of data has greater chance of capturing wide-ranging effects of favourable and unfavourable events of history on returns of individual asset classes. Since participants are likely to be concerned with the effect of inflation on the value of their retirement wealth, we have used an updated version of the dataset of real annual returns on stocks, bonds, and bills originally compiled by Dimson, Marsh, and Staunton (2002) and commercially available through Ibbotson Associates for 16 countries including Australia for a period of 105 years spanning from 1900 to 2004. All returns include reinvested income and capital gains.

\section{[INSERT TABLE 1a ABOUT HERE]}

\section{[INSERT TABLE 1b ABOUT HERE]}

Table 1a presents the summary statistics for the real returns from the three asset classes. For the full 105 year period from 1900 to 2004, the mean annual real return for Australian stocks has been $9.09 \%$ while the same for Australian bonds and bills has been $2.27 \%$ and $0.72 \%$ respectively. ${ }^{8}$ When we consider only data after the Second World War, from 1947 through 2004, the mean annual real returns for the three asset classes were smaller, recorded at $8.05 \%$, $1.08 \%$, and $0.62 \%$ for stocks, bonds, and bills respectively. However, real returns for all three classes seem to have been significantly higher in recent times. During the most recent 30 year period in our dataset, 1975 through 2004, mean annual real returns for stocks, bonds, and bills have been $10.93 \%, 4.97 \%$, and $3.20 \%$ respectively.

Expectedly, the higher mean real returns from stocks also results in higher standard

\footnotetext{
${ }^{8}$ A recent study by Brailsford, Handley, and Maheswaran (2008) estimates slightly lower equity premium over bonds and bills for the period 1883-2005 than that suggested by our data for the period 1900-2004.
} 
deviation in comparison to the returns from bonds and bills. The standard deviation of annual real returns on stocks, bonds, and bills has been 17.74\%, 13.36\%, and 5.51\% from 1900 through 2004. The corresponding estimates for post war period (1947-2004) were $21.06 \%, 11.47 \%$, and $5.09 \%$ while those for most recent 30-year period (1975-2004) were 20.54\%, $11.13 \%$, and $3.76 \%$.

The correlation between the three asset classes are provided in Table 1b. For the full period (1900-2004) data, stocks show weak positive correlation with both bonds and bills at 0.3389 and 0.2524 respectively. The correlation between bonds and bills is, expectedly, stronger at 0.6344. For the post war period (1947-2004), there is very little change in these cross asset correlations from those observed in the full period data. However, during the most recent 30-year period, the correlations between the three asset classes drop significantly. The correlations between stocks and the fixed income asset categories are almost non-existent during this period ( 0.05 with bonds and -0.06 with bills). The correlation between bonds and bills also decline to 0.42 .

Since DC plan participants have long investment horizons, typically between 30 and 40 years, we calculate the holding period returns for the different asset classes over such periods. From 1900 through to 2004, there are 76 overlapping 30 year holding periods and 66 overlapping 40 year holding periods. We find that the real returns from bonds have been negative for 29 of the 76 observed 30 year holding periods and for 20 out of 66 observed 40 -year holding periods. Bills recorded further underperformance with 32 of the 76 observed 30-year holding periods and 20 of the 66 observed 40-year holding periods yielding negative real returns for the investors. In contrast, the real returns from Australian stocks for every 30-year and 40-year holding period between 1900 and 2004 were positive. The real equity premium over bond and bills has also been positive for each of these holding periods. It is, however, to be borne in mind that these 30 year and 40 year holding periods within the historical data are overlapping and therefore returns from the asset classes for different periods are not independent of each other.

We examine data on default investment strategy for major Australian superannuation funds. ${ }^{9}$ Most superannuation funds offer a balanced diversified investment strategy to their member participants as the default investment choice. At the end of June 2008, the majority of

\footnotetext{
${ }^{9}$ In Australia, it is a regulatory requirement for trustees to identify a default strategy where investment choice is offered to standard employer-sponsored members.
} 
default strategy assets of superannuation funds were held in stocks: $29.3 \%$ in Australian stocks and $22.7 \%$ in international stocks. A further $10.6 \%$ was invested in Australian fixed interest, $5.7 \%$ in international fixed interest, $8.6 \%$ in cash, $10 \%$ in listed and unlisted property, and $13 \%$ in other assets (APRA, 2008). In 2005-06, SuperRatings, an independent research house, conducted a comprehensive analysis of 120 superannuation funds most of which hold more than $\$ 500$ million of assets. ${ }^{10}$ Together, the funds covered in excess of $\$ 300$ billion of retirement savings on behalf of nearly 10 million member accounts. The funds were rated on the basis of their performance by aggregating several factors including investment methodology, returns, fees, administration and governance/risk framework. Seventeen of these funds (representing the top $15 \%$ of their universe) received the highest or 'platinum' rating. An examination of the asset allocation data for individual default investment strategies for these 'platinum rated' funds revealed that allocation ranged from $64 \%$ to $93 \%$ for stocks, from $4 \%$ to $36 \%$ for bonds, and from nil to $15 \%$ for cash. ${ }^{11}$ Most Australian superannuation funds offer static fixed weight allocation strategies as investment options to members. Of the seventeen platinum rated funds mentioned above, only three were found to change the asset allocation of their default investment strategies with the age of the participant.

Out of the seventeen 'platinum' rated funds used in our analysis, default options of eight funds allocated less than $70 \%$ of their assets to stocks which typically represents a balanced diversified fund. Four funds had their default strategy's allocation to stocks between $70 \%$ and $80 \%$ while the default strategies of remaining five funds had more than $80 \%$ of assets invested to stocks. Based on the observed asset allocation of the default options of these seventeen 'platinum rated' funds, we form three stylised default asset allocation strategies. The first of these is called a 'defensive' strategy which represents the average allocation of the default options of the eight funds with less than $70 \%$ allocation to stocks. The next one is called a 'moderate' strategy and it has the average asset allocation of the default options of the four funds whose allocation to equities range from $70 \%$ to less than $80 \%$. Finally, we form an 'aggressive' strategy which represents the average allocation of the default options of the five funds with $80 \%$ or more allocated to equities. In addition, we examine two hypothetical strategies: (i) default option

\footnotetext{
${ }^{10}$ More details of the survey and rankings are available on SuperRating's website, www.superratings.com.au

${ }^{11}$ The information is collected from the product disclosure statements available in the respective websites of these funds as on March 2006. These funds are not named individually with their individual asset allocations in this paper. However, the same can be made available by the authors on request.
} 
average (DOA) strategy whose allocation is the same as the average allocation of default options for all Australian superannuation funds as of June 2008 (APRA, 2008); and, (ii) the 100\% stocks strategy.

\section{[INSERT TABLE 2 ABOUT HERE]}

Initially we conduct our analysis under the assumption that the DC plan assets are invested in Australian stocks, bonds, and bills. Allocations of the default options to international stocks and international bonds are, therefore, included in domestic stocks and bonds respectively. We, later, repeat the simulations by including international stocks and international bonds as separate asset classes but do not present the results here since these lead to very similar conclusions. ${ }^{12}$ Although 'property' is an important asset class for investment by these funds, we do not include it as a separate asset class in our analysis because of the paucity of reliable long-term return data. Similarly 'alternative investments' cannot be included because of the lack of specific information on their composition and therefore of any reliable index to measure returns. While examining investment strategies of Australian superannuation funds, we handle their allocation component to 'properties' and 'alternative investments' in a manner similar to that of other well-known studies including Brinson et. al., (1986) and Arshanapalli, Coggin, and Nelson (2001), where the percentage allotted to 'others' is divided between equities, bonds and bills on a pro-rata basis. However, we choose to direct the allocations against 'property' and 'alternative investments' only to equities and bonds (and not bills) on a pro-rata basis, because we believe that the riskreturn profile of these asset classes is far removed from that of bills (cash). The asset allocations for all five strategies included in our analysis are provided in Table 2.

\section{Simulation EXPERIMENTS AND RESUlts}

Based on the wealth accumulation model described earlier, we simulate RWR outcome for all the five asset allocation strategies. For both Monte Carlo and Bootstrap sets of experiments,

\footnotetext{
12 This may be due to the reason that we use US stocks and US bonds, which are highly correlated with their Australian counterparts, as proxies for international stocks and international bonds.
} 
we conduct 5,000 iterations for every asset allocation strategy under consideration to generate 5,000 different investment return paths over 40-year periods. These simulated returns are applied every year on corresponding cash flows in the participant's account to produce a range of 5,000 RWR outcomes under every strategy at the end of the 40-year horizon. Each set of experiments is initially conducted based on historical asset class returns for the entire period of available data, 1900 through 2004. However, it is quite possible that structural changes in the domestic and the international economy may render data from the very distant past, especially before the Second World War, less relevant in projecting future asset class returns. Therefore, we repeat the simulations using two more recent datasets: one for the entire post-war period (1947-2004) and another for the most recent 30 year period (1975-2004). Since the estimates obtained by the Monte Carlo and the bootstrap resampling experiments are very similar, we report only the results of the former in Tables 3,4 , and $5 .{ }^{13}$

We set the wealth accumulation target $R W R_{T}$ for the plan participant at 8.0 i.e. $800 \%$ of salary at retirement. Booth and Yakoubov (2000) uses a target wealth of 500\% of salary at retirement which translates into a $R W R_{T}$ of 5.0. Although there is no consensus on what can be considered as an adequate wealth to income ratio for Australian retirees, we choose to set $R W R_{T}$ at a higher level for two reasons. First, several commentators consider the current wealth to income levels as grossly inadequate in view of increasing life expectancy and growing health care costs. Second, since our study ignores the taxes on retirement savings and investment returns as well as transaction costs while modelling terminal wealth outcomes, we feel the need to compensate it by setting the target wealth outcome on the higher side. However, setting $R W R_{T}$ at a different value is not expected to alter the relative ranking of asset allocation strategies as long as we hold it constant for all the simulations.

\section{A. RWR Distribution}

The distribution of RWR for each asset allocation strategy provides us with the range of wealth outcomes the participant may expect to confront at the point of retirement. In addition to

\footnotetext{
${ }^{13}$ Results of the bootstrap resampling experiments can be obtained by contacting the authors.
} 
mean and median RWR, we estimate the first and third quartile estimates of the distribution for every allocation strategy to assess their relative appeal. Table 3 provides the distribution parameters of RWR for each of the asset allocation strategies. The results indicate that RWR varies significantly across asset allocation strategies. The mean and the median RWR seem to increase for strategies with higher allocation to stocks and are highest for the strategy which invests entirely in stocks. The median RWR for the $100 \%$ stocks strategy is over $50 \%$ higher than that of DOA strategy, which only has two-thirds of assets invested in stocks.

\section{[INSERT TABLE 3 ABOUT HERE]}

The first and third quartile outcomes also tend to increase as we move from strategies with lower proportion of stocks to those with higher proportion of stocks. The difference between first quartile outcomes of different strategies are relatively smaller compared to the spread between the third quartile outcomes. For example, the first quartile outcomes for the defensive and aggressive strategies are 5.80 and 6.98 respectively. The corresponding estimates for their third quartile outcomes are 12.17 and 16.98. Again, the 100\% stocks strategy results in the best first and third quartile RWR outcomes. The aggressive strategy has higher maximum RWR outcome relative to moderate and defensive strategy. It also has the same minimum RWR outcome as that of the defensive strategy and slightly higher than that of the moderate strategy. Also, the minimum outcomes for different strategies lie within a narrow range (0.57 to 1.13) which shows that there is not much to choose between the strategies on the basis of their worst (out of 5000) outcomes.

The results of Monte Carlo simulations using returns data for 1947-2004 and 1975-2004 give similar indications about the effect of asset allocation strategies on terminal wealth outcomes. While the RWR estimates for various strategies vary when we use data for different periods, strategies with higher allocations to stocks consistently dominate those with lower allocation to stocks in terms of mean, median, first quartile, and third quartile outcomes. As before, the $100 \%$ stocks strategy result in the best outcomes for all these parameters except the first quartile outcome for the simulations using 1975-2004 data where the best result is produced by the aggressive strategy.

Our simulations produce a range of possible RWR outcomes for every strategy. The estimates for both CV and IQRR indicate that the dispersion of RWR outcomes tends to increase 
with higher allocation to stocks although the rate of increase seems to be very small. For instance, the IQRR for the defensive strategy is 0.76 while that for the aggressive strategy is 0.92. The $100 \%$ stocks strategy produces an IQRR of 1.06 . These estimates indicate that the disparity in wealth outcomes between the cohorts who meet very positive investment return scenarios and those who confront relatively unfavourable investment returns during their employment life while being enrolled in the same default option may be dependent on the allocation policy of the plan. Nevertheless, the difference in disparity across cohorts for strategies with different proportions of stocks does not appear to be very large. The simulation results using data for recent periods also support these findings.

\section{B. Downside Risk and Risk-Adjusted Performance Estimates}

We use lower partial moments with risk aversion parameters 0,1 , and 2 so that the investors with different levels of risk tolerance can use these estimates to evaluate alternative asset allocation strategies. Table 4 reports the downside risk estimates for RWR under different asset allocation strategies.

\section{[INSERT TABLE 4 ABOUT HERE]}

Estimates for all the $L P M$ measures steadily increase with a decrease in allocation to stocks indicating a clear inverse relationship. For instance, the $L P M_{0}$ for the defensive strategy with $66 \%$ allocation to stocks is 0.4719 which indicates that there is a $47.19 \%$ probability that the RWR would fall below $R W R_{T}$. In comparison, the probability of shortfall for the moderate strategy with $76 \%$ stocks is 0.392 and for the aggressive strategy with $85 \%$ stocks is 0.324 . Interestingly, the $100 \%$ stocks strategy has only 0.2622 , or around one-in-four, probability of falling below $R W R_{T}$, which is the lowest of all strategies, while DOA strategy has almost $47 \%$ chance of underperforming that target.

Similar trends are also observed for measures of magnitude of shortfall $\left(L P M_{1}\right)$ and below target semivariance $\left(\mathrm{LPM}_{2}\right)$ indicating that the downside risk gets reduced by increasing allocation to stocks in the portfolio. In fact, the decline in downside risk with increased exposure to stocks appears to be more pronounced for the higher order LPM measures i.e. more averse the participants are to the downside risk of failing to meet their wealth accumulation objective, more 
appealing would the aggressive strategies be relative to moderate or defensive strategies.

Simulation results using post-war data also suggest that $L P M$ estimates are smaller for strategies with higher allocation to stocks. However, the results are not as conclusive when we use recent 30-year returns (1975-2004) data as simulation input. While the $L P M_{0}$ estimates are still lower for more aggressive strategies, albeit by a much smaller margin, this is not true for $L P M_{1}$ and $L P M_{2}$. The estimates for $L P M_{1}$ do not exhibit any clear trend with similar estimates observed for strategies with significantly different proportion of stocks. For $L P M_{2}$, the estimates are generally lower for strategies holding lower proportion of stocks.

While the terminal wealth outcomes and associated risks involved with each allocation strategy under consideration can be assessed from the parameters of the simulated RWR distribution and various measures of LPM, composite performance measures are essential to rank the strategies based on overall risk-reward profile. We compute estimates for SR and UPR, performance measures that are adjusted for downside risk and also produce these results in Table 4. For simulations using full period data, SR and UPR are generally found to increase with rising proportion of stocks in the strategy. The $100 \%$ stocks strategy results in the highest SR and UPR.

The above results come as no surprise since we earlier found strategies with higher stock allocation to be superior in terms of terminal wealth outcomes as well as downside risk based on our simulation with the full period (as well as post war period) data. Of more interest is the performance estimates for simulations using data for the recent 30 year sub-period because downside risk estimates in its case lead to different conclusions for $L P M_{1}$ and $L P M_{2}$. However, we find that the risk-adjusted performance estimates for the sub-periods are supportive of the rankings indicated by the full-period simulation. Estimates for both SR and UPR in these cases indicate that an allocation rule dominated by stocks results in better risk adjusted performance and therefore, are consistent with the findings based on simulation using full period data.

\section{Tail-Related Risk Estimates}

As discussed previously in this paper, it is plausible that plan participants may care more about the most adverse outcomes that can occur for a given strategy. Plan providers in that case 
are likely to select a strategy which maximizes the worst ' $n$ ' percentile of outcomes. In this paper, we estimate VaR and ETL at 95\% confidence level, which means we assume that the participants are concerned about the worst 5\% of RWR outcomes. ${ }^{14}$ For participants who are concerned about outcomes falling below $5^{\text {th }}$ percentile, the ETL measure provides the expected value of such an outcome.

\section{[INSERT TABLE 5 ABOUT HERE]}

The results for VaR and ETL estimates are produced in Table 5. The results for simulations using full period data do not show a clear trend. More importantly, it is observed that the difference between the VaR estimates of different asset allocation strategies is very small. The lowest observed VaR estimate is 3.3936 given by the defensive strategy. This means that by employing this strategy there is a 5\% (or one-in-twenty) chance of the RWR falling below 3.3936. At 3.3961, the aggressive strategy fares marginally better. The highest VaR estimate (4.0033) is produced by the $100 \%$ stocks strategy which goes against the conventional logic that stocks, being most volatile among the asset classes, can potentially result in the most adverse outcomes. The results for ETL also support these conclusions.

The simulation results based on data for other periods present a slightly different picture but do not alter the fundamental conclusion of the previous simulation. Using data for 19472004 period, the VaR estimates of the strategies are found to lie within a very close range (2.4100-2.5638) and do not seem to follow any clear pattern. The $100 \%$ stocks strategy produces a VaR estimate of 2.41 which is almost the same as that of the defensive strategy but slightly lower than that of DOA strategy which produces a VaR estimate of 2.5196. The moderate strategy produces the highest estimates for both the VaR and the ETL.

Simulation with data for 1975-2004 period results for VaR and ETL estimates also presents a mixed picture. The range of VaR estimates for different strategies is still very narrow. The lowest estimate of 4.3970 is given by the $100 \%$ stocks strategy while the highest estimate of 5.2719 is produced by the moderate strategy. It is easy to see that the gap between these two situations can hardly be considered as the difference between a ruinous and a non-ruinous outcome. This is confirmed by the ETL estimates which range from 3.2636 to 4.2175 indicating

\footnotetext{
${ }^{14}$ While it is theoretically possible that some participants may have greater degree of extreme risk aversion and consider RWR outcomes below an even lower threshold (say $1 \%$ ), we believe the $5^{\text {th }}$ percentile outcome would be adequate for majority of
} 
even the below $5 \%$ outcomes are not very different between different allocation strategies. Thus our evidence clearly implies that the risk of confronting extremely poor retirement wealth outcomes may not be very sensitive to the choice of asset allocation strategy.

Our results, undoubtedly, have been influenced by the large premium that Australian stocks have enjoyed historically over bonds and bills. By using long term return data for asset classes over a hundred years, we have attempted to ensure that our results are not biased by returns for any asset class in a particularly favourable (or unfavourable) period. Yet, as many commentators have observed, even a century long dataset may be inadequate to predict the entire gamut of future possibilities. Many financial economists in recent years have also opined that the high returns from equity investments experienced in the twentieth century are unlikely to be repeated. For example, Siegel (2002) expects future real returns on stocks to be lower by 1 - $2 \%$. Dimson et al. (2002) estimates the average future equity risk premium for 16 countries including Australia and indicates an expected fall by $1.8 \%$ from historical risk premium.

Following other simulation studies including Shiller (2005) and Poterba et. al., (2006), we run a repeat set of Monte Carlo trials by lowering the returns on Australian stocks for every year in our data set by $2 \% .^{15}$ Expectedly, this set of trials produces lower retirement wealth estimates for all strategies under consideration as they have significant, albeit varying degree of allocation to equities. The gaps between different RWR estimates of the aggressive strategies and those of the relatively conservative strategies in our dataset, however, show a marked decline. For example, the median RWR for $100 \%$ stocks strategy is now $33 \%$ higher compared to the DOA strategy while in the previous set of simulations with unadjusted equity premium, the former outperformed the latter by $50 \%$.

The results for downside risk and tail risk estimates tell a similar story. With the downward revision of equity premium, the probability of falling below $R W R_{T}$ increases for all the strategies. The $100 \%$ stocks strategy still comes out as the best performer with about $48 \%$ probability of shortfall while the DOA strategy is way behind at $68 \%$. Again the aggressive strategy fares better than the moderate or defensive strategies on downside risk adjusted basis as given by the estimates for Sortino and UPR. In terms of VaR and ETL, however, the estimates for different

\footnotetext{
participants.

${ }^{15}$ These studies conduct two parallel sets of simulations: one with historical returns on stock, bond, and bills and an alternative series where returns on stocks are reduced by a few percentage points (2-3\%) to allow for the possibility of smaller equity premium in future.
} 
asset allocation strategies are extremely close. The DOA strategy produces VaR and ETL estimates of 2.72 and 2.30 respectively which are marginally higher than the corresponding estimates of 2.66 and 2.11 produced by the $100 \%$ stocks strategy. ${ }^{16}$

\section{CONCLUSION}

Given the fact that Australian stocks have significantly outperformed fixed income securities over long horizons in the past, it is no surprise that differences between various default investment options with respect to their exposure to stocks result in large differences in simulated terminal wealth outcomes for DC plan participants. More revealing is our finding that very high allocations to stocks may actually prove to be less risky on most occasions if risk is viewed in the context of falling short of the participant's wealth accumulation target, in terms of both probability and magnitude of shortfall. Our findings, although based on simulated wealth outcomes using historical return data for Australian asset classes, may have important implications for retirement plans in other industrialised nations as the returns on various asset classes in many of these markets have displayed broadly similar trends over the last century (Dimson et. al., 2002).

At present, regulators in most countries, including Australia, do not prescribe any asset allocation structure for default investment options. But very often they emphasise the importance of diversification in coping with risk by optimizing its trade-off with returns. Our results, however, show that very long term investors like DC plan participants have higher likelihood of being better off by concentrating their investments in stocks alone. We have demonstrated that the strategies that are heavily tilted towards stocks not only reduce the chance of failure in meeting the participants' wealth accumulation target but also seem to diminish the extent of shortfall in case the participants fail to achieve such objective. At the same time, they seem to offer strong upside potential of generating terminal wealth outcomes that outperform the participant's accumulation target at retirement. It seems that balanced diversified strategies nominated by many plan providers in Australia as default investment options, which bear close resemblance to the 'defensive' strategy in our paper, may not be well suited to optimise the retirement benefits of the participants. The problem may be even more serious for countries such

\footnotetext{
${ }^{16}$ The full results for this set of simulation trials can be made available by the authors on request.
} 
as the USA, where DC plans have typically adopted an even more conservative approach in designing their default option.

Perhaps the most powerful evidence against selecting balanced diversified strategies or even moderately aggressive strategies as default options is provided by our results for tail-related risk. As stock returns are essentially considered to be more volatile than other asset class returns, one would have normally expected their presence in the portfolio to cause more extreme outcomes. However, our results indicate that the extreme wealth outcomes occur mostly at the upper tail of the wealth distribution, which is actually favourable to the plan participant. The measures for the extreme outcomes at the lower tail of retirement wealth distribution suggest that higher allocation to stocks do not necessarily increase the risk of confronting these adverse outcomes and in some cases, may even reduce their severity. In our study, the risk of extremely adverse outcomes does not seem to vary considerably with change of asset allocation which implies that extreme loss aversion should have minimal role to play in the asset allocation decision for default investment options.

The risk of investing in equities has been bought into sharp focus by the recent period which has come to be labelled as the Global Financial Crisis (GFC). Does this undermine the results obtained in this paper? We do not think this to be true due to two reasons. First, the current slide in the stock market is still far below that witnessed during the Great Depression era, data from which have been included in our simulations. Second, as DeLong (2008) points out, a sharp downturn in stock prices due to sudden increase in perceived risk which is not accompanied by persistent collapses in corporate earnings of similar order is likely to be temporary in nature. Such situations actually present a stronger reason for long horizon investors to tilt their portfolios towards stocks. If the worst case scenario of steep and persistent fall in corporate earnings plays out in reality, bonds are not likely to prove any safer. Also, in such an environment, several doses of government fiscal packages to boost the economy would possibly result in inflation and massively erode the real wealth of bond investments. We posit that the larger question for those designing default options today relates to the management of asset allocation decision over the life course. Issues surrounding traditional lifecycle investing (Basu and Drew, 2009) and, more recently, dynamic lifecycle investing (see Basu, Byrne and Drew, 2009) provide both interesting and important directions for future default option design. 


\section{REFERENCES}

Arshanapalli, B., Coggin, T., and Nelson, W. (2001), 'Is fixed-weight asset allocation really better?', Journal of Portfolio Management, vol. 27, pp. 27- 38.

Artzner, P., Delbaen, F., Eber, J., and Heath, D. (1999), 'Coherent measures of risk', Mathematical Finance, vol. 9, pp. 203-28.

ABS (2005) Year Book Australia, 2005, Australian Bureau of Statistics, Canberra.

APRA (2008), Annual Superannuation Bulletin, Australian Prudential Regulation Authority, Sydney.

Baker, A., Logue, D., and Rader, J. (2005) Managing Pension and Retirement Plans: A Guide for Employers, Administrators, and Other Fiduciaries, New York: Oxford University Press.

Basu, A., Byrne, A., and Drew, M., 2009, Dynamic Lifecycle Strategies for Target Date Retirement Funds, (February 6, 2009). , <accessed $15^{\text {th }}$ January 2010 http://ssrn.com/abstract=1302586>

Basu, A., and Drew, M., 2009, 'Portfolio size effect in retirement accounts: What does it imply for lifecycle asset allocation funds?' Journal of Portfolio Management, vol. 35, pp. 61-72.

Bawa, V. (1975), 'Optimal rules for ordering uncertain prospects', Journal of Financial Economics, vol. 2, pp. 95121.

Bawa, V. (1978), 'Safety first, stochastic dominance, and optimal portfolio choice', Journal of Financial and Quantitative Analysis, vol. 13, pp. 255-71.

Beshears, J., Choi, J., Laibson, D., and Madrian, B. (2006), 'The Importance of default options for retirement savings outcomes: Evidence from the United States', National Bureau of Economic Research Working Paper No. 12009.

Blake, D., Byrne, A., Cairns, A. and Dowd, K. (2004), 'The stakeholder pension lottery: An analysis of the default funds in UK stakeholder pension schemes', Pensions Institute Discussion Paper No. PI-0411.

Blake, D., Lehmann, B. and Timmermann, A. (1999), 'Asset allocation dynamics and pension fund performance', Journal of Business, vol. 72, pp. 429-61.

Brailsford, T., Handley, John C. and Maheswaran, K. (2008). Re-examination of the historical equity risk premium in Australia. Accounting and Finance 48(1), pp. 73-98

Bridgeland, S. (2002), 'Choices, choices', Pension Management Institute Trustee Group News, pp. 3-5.

Brinson, G., Hood, R. and Beebower, G. (1986), 'Determinants of portfolio performance', Financial Analysts Journal, vol. 42, pp. 39-44.

Booth, P. and Yakoubov, Y. (2000), 'Investment policy for defined-contribution pension scheme members close to retirement: An analysis of the "lifestyle" concept', North American Actuarial Journal, vol.4, pp. 1-19

Choi, J., Laibson, D., Madrian, B., and Metrick, A. (2003), 'For better or for worse: Default effects and 401 (k) savings behavior, in (David Wise, ed.), Perspectives in the Economics of Aging, Chicago: University of Chicago Press,.

Cronqvist, H, and Thaler, R. (2004), 'Design choices in privatized social-security systems: Learning from the Swedish experience', American Economic Review, vol. 94, pp. 424-8.

DeLong, J. (2008), 'Stocks for the long run', Economists' Voice, vol. 5, Article 2. 
Dimson, E., Marsh, P., and Staunton, M. (2002) Triumph of the Optimists: 101 Years of Global Investment Returns, Princeton: Princeton University Press.

Dowd, K. and Blake, D. (2006) 'After VaR: The theory, estimation, and insurance applications of quantile-based risk measures', Journal of Risk and Insurance, Vol. 73, pp. 193-229.

Fishburn, P. (1977), 'Mean-risk analysis with risk associated with below-target returns', American Economic Review, vol. 67, pp. 116-26.

Harlow, W. and Rao, R. (1989), 'Asset pricing in a generalized mean-lower partial moment framework: Theory and evidence', Journal of Financial and Quantitative Analysis, vol. 24, pp. 285-312.

Kryger, Tony, 1999, 'The risk of unemployment', Parliament of Australia Research Note 16 (1998-99).

Madrian, B. and Shea, D (2001), 'The power of suggestion: Inertia in 401(k) participation and savings behaviour', vol. 116, pp.1149-87.

Mao, J. (1970), 'Models of capital budgeting, E-V vs. E-S', Journal of Financial and Quantitative Analysis, vol. 5, pp. 657-76.

Olsen, R. (1997), 'Investment risk: The experts' perspective', Financial Analysts Journal, vol. 53, 62-6.

Poterba, J., Roth, J., Venti, S., and Wise, D. (2006), 'Lifecycle asset allocation strategies and the distribution of 401 (k) retirement wealth', National Bureau of Economic Research Working Paper No. 11974.

Rabin, M., and Thaler, R. (2001), 'Anomalies: Risk aversion', Journal of Economic Perspectives, vol. 15, pp. 21932 .

Richardson, S. (2006), 'Unemployment in Australia', National Institute of Labour Studies Discussion Paper.

Roy, A. (1952), 'Safety first and the holding of assets', Econometrica, vol. 20, pp. 431-49.

Shiller, R. (2005), 'Lifecycle portfolios as government policy', The Economists' Voice, vol 2, article 14.

Sortino, F., Van der Meer, R. and Plantinga, A. (1999), 'The Dutch triangle', Journal of Portfolio Management, vol. 26, 50-58.

Sortino, F., and Price, L. (1994), 'Performance measurement in a downside risk framework', Journal of Investing, vol. 3, 59-64.

Statman, M., and Shefrin, H. (2000), 'Behavioral portfolio theory', Journal of Financial and Quantitative Analysis $35,127-51$.

Utkus, S. (2004), 'Selecting a default fund for defined contribution plan', Vanguard Centre for Retirement Research, vol. 14, 1-19. 


\section{Table 1a}

Summary Statistics of Real Returns for Australian Stocks, Bonds, and Bills

\begin{tabular}{lccc}
\hline & Stocks & Bonds & Bills \\
\hline & & & \\
\cline { 2 - 3 } & PANEL A: 1900-2004 DATA & \\
Mean & & & \\
Median & 0.0909 & 0.0226 & 0.0072 \\
Maximum & 0.1100 & 0.0200 & 0.0100 \\
Minimum & 0.5100 & 0.6200 & 0.1800 \\
Standard Deviation & -0.3800 & -0.2700 & -0.1600 \\
& 0.1774 & 0.1336 & 0.0551
\end{tabular}

PANEL B: 1947-2004 DATA

$\begin{array}{lccc}\text { Mean } & 0.0805 & 0.0108 & 0.0062 \\ \text { Median } & 0.1050 & 0.0200 & 0.0150 \\ \text { Maximum } & 0.5100 & 0.2700 & 0.0900 \\ \text { Minimum } & -0.3800 & -0.2700 & -0.1600 \\ \text { Standard Deviation } & 0.2106 & 0.1146 & 0.0508\end{array}$

PANEL C: 1975-2004 DATA

\begin{tabular}{lccc} 
Mean & 0.1093 & 0.0496 & 0.0320 \\
Median & 0.1150 & 0.0900 & 0.0300 \\
Maximum & 0.5100 & 0.2700 & 0.0900 \\
Minimum & -0.2300 & -0.1900 & -0.0600 \\
Standard Deviation & 0.2053 & 0.1113 & 0.0376 \\
\hline
\end{tabular}

This table presents the summary statistics of annual real returns for Australian stocks, bonds, and bills for the full sample period 1900-2004 and two sub-sample periods 1947-2004 and 1975-2004. Source: Dimson, Marsh and Staunton (2002) and updates from Ibbotson Associates. 


\section{Table 1b}

Correlation between Real Returns for Australian Stocks, Bonds, and Bills

\begin{tabular}{lccc}
\hline & Stocks & Bonds & Bills \\
\hline \multicolumn{3}{c}{ PANEL A: 1900-2004 DATA } \\
\cline { 2 - 3 } Stocks & 1.0000 & 0.3389 & 0.2524 \\
Bonds & 0.3389 & 1.0000 & 0.6344 \\
Bills & 0.2524 & 0.6344 & 1.0000
\end{tabular}

PANEL B: 1947-2004 DATA

$\begin{array}{llll}\text { Stocks } & 1.0000 & 0.3237 & 0.2113 \\ \text { Bonds } & 0.3237 & 1.0000 & 0.6406 \\ \text { Bills } & 0.2113 & 0.6406 & 1.0000\end{array}$

PANEL C: 1975-2004 DATA

\begin{tabular}{lccc} 
Stocks & 1.0000 & 0.0542 & -0.0671 \\
Bonds & 0.0542 & 1.0000 & 0.4207 \\
Bills & -0.0671 & 0.4207 & 1.0000 \\
\hline
\end{tabular}

This table presents the correlation coefficients between annual real returns for Australian stocks, bonds, and bills for the full sample period 1900-2004 and two sub-sample periods 1947-2004 and 1975-2004 


\section{Table 2}

Asset Allocation of Stylized Default Investment Options

\begin{tabular}{lccc}
\hline STRATEGIES & Stocks $(\%)$ & Bonds $(\%)$ & Cash $(\%)$ \\
\hline Defensive & 66 & 29 & 5 \\
Moderate & 76 & 22 & 2 \\
Aggressive & 85 & 13 & 2 \\
Default Option Average & 67 & 26 & 7 \\
$100 \%$ Stocks & 100 & 0 & 0 \\
\hline
\end{tabular}

This table provides the asset allocation of the three stylised investment strategies (defensive, moderate, and aggressive), the default option average (DOA) strategy and 100\% stocks strategy. The asset allocation of the 'defensive' strategy represents the average asset allocation of the default investment options of the eight 'platinum rated' funds whose allocation to stocks is less than $70 \%$. The 'moderate strategy's asset allocation is the average of the default investment options of the four 'platinum rated' funds whose allocation to stocks is between $70 \%$ and $80 \%$. The 'aggressive' strategy has an asset allocation which is the average asset allocation of the default investment options of the five 'platinum rated' funds whose allocation to stocks is above $80 \%$. 


\section{Table 3}

Distribution Parameters of Retirement Wealth Ratio (RWR)

\begin{tabular}{|c|c|c|c|c|c|c|c|c|}
\hline STRATEGIES & Mean & Median & Max. & Min. & $\mathrm{Q} 1$ & Q3 & $\mathrm{CV}$ & IQRR \\
\hline \multicolumn{9}{|c|}{ PANEL A: SiMULATION RESULTS BASED ON 1900-2004 DATA } \\
\hline Defensive & 9.87 & 8.34 & 81.11 & 1.38 & 5.80 & 12.17 & 0.62 & 0.76 \\
\hline Moderate & 11.63 & 9.49 & 92.89 & 1.26 & 6.34 & 14.51 & 0.69 & 0.86 \\
\hline Aggressive & 13.71 & 10.91 & 129.16 & 1.38 & 6.98 & 16.98 & 0.75 & 0.92 \\
\hline Default Option Average & 9.90 & 8.37 & 72.27 & 1.69 & 5.84 & 12.34 & 0.62 & 0.78 \\
\hline $100 \%$ Stocks & 17.37 & 12.88 & 194.55 & 1.13 & 7.78 & 21.48 & 0.90 & 1.06 \\
\hline
\end{tabular}

PANel B: Simulation Results BaSed ON 1947-2004 Data

$\begin{array}{lcccccccc}\text { Defensive } & 7.76 & 6.32 & 77.41 & 0.93 & 4.22 & 9.53 & 0.71 & 0.84 \\ \text { Moderate } & 9.09 & 6.98 & 101.60 & 0.90 & 4.51 & 11.31 & 0.81 & 0.98 \\ \text { Aggressive } & 10.76 & 7.81 & 179.96 & 0.74 & 4.75 & 13.07 & 0.96 & 1.06 \\ \text { Default Option Average } & 7.77 & 6.31 & 87.21 & 0.99 & 4.29 & 9.49 & 0.71 & 0.82 \\ 100 \% \text { Stocks } & 13.63 & 8.92 & 228.03 & 0.76 & 5.11 & 16.54 & 1.14 & 1.28\end{array}$

PANel C: Simulation Results BASEd ON 1975-2004 Data

\begin{tabular}{lcccccccc} 
Defensive & 16.42 & 13.50 & 146.22 & 1.81 & 9.04 & 20.44 & 0.69 & 0.84 \\
Moderate & 19.29 & 15.09 & 249.66 & 1.48 & 9.60 & 23.84 & 0.81 & 0.94 \\
Aggressive & 22.45 & 16.42 & 346.70 & 1.31 & 9.90 & 27.76 & 0.92 & 1.08 \\
Default Option Average & 16.32 & 13.42 & 130.57 & 1.71 & 8.97 & 20.40 & 0.68 & 0.85 \\
$100 \%$ Stocks & 28.15 & 18.17 & 460.72 & 1.34 & 9.78 & 33.45 & 1.19 & 1.30 \\
\hline
\end{tabular}

Table 3 reports the distribution of RWR from the Monte Carlo simulation (multivariate normal). A total of 5,000 iterations for every asset allocation strategy under consideration has been conducted to generate different investment return paths over 40-year periods. Max., Min., Q1, and Q3 denote maximum, minimum, first quartile, and third quartile RWR outcomes respectively. CV and IQRR measure the dispersion of RWR outcomes and represent coefficient of variation and interquartile range ratio for the distribution of RWR outcomes respectively. 
Table 4

Estimates for Downside Risk and Performance Measures

\begin{tabular}{|c|c|c|c|c|c|}
\hline STRATEGIES & $L P M_{0}$ & $L P M_{1}$ & $L P M_{2}$ & $S R$ & $U P R$ \\
\hline \multicolumn{6}{|c|}{ PANEL A: SIMULATION RESULTS BASED ON 1900-2004 DATA } \\
\hline Defensive & 0.4719 & 1.1608 & 3.9099 & 0.9465 & 1.5335 \\
\hline Moderate & 0.3920 & 0.9510 & 3.2046 & 2.0339 & 2.5650 \\
\hline Aggressive & 0.3240 & 0.7813 & 2.6410 & 3.5427 & 4.0229 \\
\hline Default Option Average & 0.4696 & 1.1455 & 3.8546 & 0.9681 & 1.5516 \\
\hline $100 \%$ Stocks & 0.2622 & 0.6415 & 2.2062 & 6.3074 & 6.7393 \\
\hline
\end{tabular}

PANEL B: Simulation ReSUlts BASEd ON 1947-2004 DATA

\begin{tabular}{|c|c|c|c|c|c|}
\hline Defensive & 0.6520 & 2.0445 & 8.2208 & -0.0840 & 0.6290 \\
\hline Moderate & 0.5773 & 1.8048 & 7.2803 & 0.4019 & 1.0708 \\
\hline Aggressive & 0.5179 & 1.6236 & 6.6785 & 1.0751 & 1.7032 \\
\hline Default Option Average & 0.6512 & 2.0240 & 8.0674 & -0.0794 & 0.6333 \\
\hline $100 \%$ Stocks & 0.4494 & 1.4613 & 6.2095 & 2.2612 & 2.8477 \\
\hline \multicolumn{6}{|c|}{ PANEL C: SIMULATION RESULTS BASED ON 1975-2004 DATA } \\
\hline Defensive & 0.1892 & 0.3738 & 1.0884 & 8.0830 & 8.4413 \\
\hline Moderate & 0.1756 & 0.3726 & 1.1485 & 10.5329 & 10.8807 \\
\hline Aggressive & 0.1688 & 0.3856 & 1.2764 & 12.7748 & 13.1164 \\
\hline Default Option Average & 0.1868 & 0.3744 & 1.1073 & 7.9102 & 8.2659 \\
\hline $100 \%$ Stocks & 0.1812 & 0.4641 & 1.6793 & 15.551 & 15.9092 \\
\hline
\end{tabular}

Table 4 reports estimates for downside risk and performance measures from the Monte Carlo simulation. $L P M_{O}, L P M_{1}$, and $L P M_{2}$ measure downside risk and represent lower partial moment with degree $(\lambda) 0,1$, and 2 respectively. The downside risk adjusted performance measures SR and UPR denote Sortino ratio and upside potential ratio respectively. A target retirement wealth ratio $\left(R W R_{T}\right)$ of 8.0 has been used in the simulations to estimate these measures. 
Table 5

Tail Risk Estimates for RWR Distribution

\begin{tabular}{lcc}
\hline STRATEgIES & VaR & ETL \\
\hline & Panel A: Simulation Results BaSED ON 1900-2004 DATA & \\
Defensive & 3.3936 & 2.8416 \\
Moderate & 3.4528 & 2.8546 \\
Aggressive & 3.3961 & 2.7940 \\
Default Option Average & 3.4616 & 2.8893 \\
100\% Stocks & 4.0033 & 3.2043 \\
\hline
\end{tabular}

PANEL B: Simulation Results BASED ON 1947-2004 Data

\begin{tabular}{lcc} 
Defensive & 2.4104 & 1.9786 \\
Moderate & 2.5638 & 2.0846 \\
Aggressive & 2.4318 & 1.9809 \\
Default Option Average & 2.5196 & 2.028 \\
$100 \%$ Stocks & 2.4100 & 1.8323 \\
\hline
\end{tabular}

PANEl C: Simulation Results BaSEd ON 1975-2004 Data

\begin{tabular}{lcc} 
Defensive & 5.0125 & 4.1038 \\
Moderate & 5.2719 & 4.2175 \\
Aggressive & 5.1698 & 4.1914 \\
Default Option Average & 5.1974 & 4.1088 \\
$100 \%$ Stocks & 4.3970 & 3.2636 \\
\hline
\end{tabular}

Table 5 reports tail risk estimates for the RWR Distribution from the Monte Carlo simulation. Value at Risk (VaR) and Expected Tail Loss (ETL) for RWR outcomes are estimated at $95 \%$ confidence level. Therefore, there is a 5\% probability of the RWR falling below the VaR estimate. Conditional to the RWR falling below VaR i.e. for the worst 5\% of RWR outcomes, the expected value is given by ETL. 